\title{
Kavşak Trafik Sinyalizasyon Kontrolü için Bulanık Mantık Yöntemi ile Gerçek Zamanlı Sistemin Tasarımı ve Uygulaması
}

\author{
Anas A. M. Harb ${ }^{1 *}$, Akif Durdu ve Hakan Terzioğlu ${ }^{3}$ \\ ${ }^{1}$ Department of Electrical - Electronic Engineering, Konya Technical University, Konya,Turkey (ORCID: 0000-0001-8311-6188) \\ 2 Department of Electrical - Electronic Engineering, Konya Technical University, Konya,Turkey (ORCID: 0000-0002-5611-2322) \\ 3 Department of Electrical and Energy, Konya Technical University, Konya,Turkey (ORCID: 0000-0001-5928-8457) \\ (harboglu@gmail.com)
}

(Bu yayın HORA 2019 kongresinde sözlü olarak sunulmuştur.)

(First received 1 August 2019 and in final form 26 October 2019)

(DOI: $10.31590 /$ ejosat.638)

Özet

Ulaşım araçları, insanların ihtiyaçlarını ve mallarını bir alandan diğer bir alana taşımak amacıyla kullanılan araçları ifade eder. Bu araçlar, eski çağlardan günümüz zamanına kadarki tüm araçları içerir. Trafikteki araç sayılarının artması, kullanılan yollar etrafındaki alanların yetersizliği ve bu yolların genişletilememesi veya alt/üst yollar yapılamaması sebebiyle akıllı trafik sinyalizasyon sistemlerine ihtiyaç duyulmaktadır. Günümüzde, trafik sistem mekanizmalarının sabit zamana bağlı olması sebebiyle trafik kontrolü yeterli değildir. Değişen trafik koşullarına tepki veren trafik sinyal sistemleri, ulaşım verimliliğini artırmak için önemli bir bileşendir. Zamanlama planlarını iyileştirmek amacıyla kaydedilen verilere dayanılarak geliştirilen bugünkü geleneksel denetleyiciler, artık zamana göre değişen trafik yoğunluğuna ve yolda artan araç sayısı nedeniyle trafik kavşaklarındaki tıkanıklığı ve bu tıkanıklığın kötü sonuçlarını önlemeye çözüm olamamaktadır. İnsan düşüncesine uyum sağlayarak ulaşımı yönlendirecek trafik denetleme mekanizmaları, Bulanık mantık, PLC ve Petri net ağları gibi teknikler kullanılarak tasarlanmaktadır. Bu çalışmada dört yollu bir kavşak için trafik ışıkların akıllı denetim mekanizması altında gerçek verilerle Bulanık Mantık (BM) yöntemi ve klasik (Sabit zaman) yöntemi kullanarak bir kontrol çalışması yapılmıştır. Yazılım kısmı için MATLAB programlama dili kullanılmıştır. Çalışma sonucunda; Bulanık mantık denetleyici ve klasik denetleyici, performanslarının sonuçları karşılaştııılmıştır. Bulanık mantık yönteminde, belirli saatlerde kavşakta bulunan her caddedeki arabaların sayısı giriş olarak belirlenmiştir. Çıkış ise bulanık mantığın kurallarına göre seçilecek cadde ve o caddedeki yeşil ışığının süresi olarak belirlenmiştir. Giriş ve çıkış parametrelerinin sayısal verileri bulanıklaştırılması, bulanık mantığın kural seti sayesinde araba sayısına göre yeşil ışığın süresi ve cadde seçiminde akıllı bir kontrol sistemi elde etmemizi sağlayabilmiştir. Aynı verileri klasik yöntemde de kullanarak, bulanık mantık yönteminin klasik yönteminden daha etkin olduğu görülmüştür.

Anahtar Kelimeler: Bulanık Mantık, Trafik Işıkları Kontrolü, Akıllı trafik Sinyalizasyonu, sabit süreli trafik kontrolü

\section{Design And Implementation of Real-Time System with Fuzzy Logic Method For Junction Traffic Signalization Control}

\begin{abstract}
A lot of vehicles have been used to transport people's needs and goods from one area to another. These tools include all the tools from ancient times to the present. Intelligent traffic signaling systems are needed due to the increase in the number of vehicles in the traffic, the insufficiency of the areas around the roads used and the inability to expand these roads or lower / upper roads. At present, traffic control is not sufficient due to the fixed time of the traffic system mechanisms. Traffic signaling systems that react to changing traffic conditions are an important component to improve transport efficiency. Based on data recorded to improve timing plans, today's traditional controllers are no longer the solution to preventing traffic congestion at traffic junctions and the adverse consequences of this congestion due to the increasing traffic density and the number of vehicles on the road. It is designed using techniques such as traffic control mechanisms, Fuzzy logic, PLC and Petri net networks to adapt to human thinking. In this study, a control study was
\end{abstract}


conducted for a four-way intersection using the Fuzzy Logic (BM) method and classical (Fixed time) method with real data under the intelligent control mechanism of traffic lights. MATLAB programming language is used for the software part. In the results of working; The results of performance of fuzzy logic controller and classical controller were compared. The exit is determined according to the rules of fuzzy logic and the duration of the green light on that street. Blurring the numerical data of the input and output parameters enabled us to obtain an intelligent control system for the duration of the green light according to the number of cars and the street selection thanks to the rule set of the fuzzy logic. Using the same data in the classical method, fuzzy logic method was found to be more effective than the classical method. In the fuzzy logic method, the number of cars on each street at the intersection was determined as the entrance at certain times.

Keywords: Fuzzy Logic, Traffic Lights Control, Intelligent Traffic Signaling, Fixed Time Traffic Control.

\section{Giriş}

Her geçen gün trafikte araba sayısı artmaktadır. Trafik tıkanıklığı ve buna bağlı olarak trafikteki arabaların saatlerce yollarda beklemeleri, büyükşehirler için önemli bir problemdir. Bu problem, ekonomik kayıplara, hava kirliliğine ve yaşam kalitesinin düşmesine sebep olmaktadır. Bu trafik problemini gidermek için, ilave yollar ve köprüler gibi daha fazla altyapı yatırımları yapılabilir. Ancak büyükşehirlerdeki plansız yapılaşma, alan eksikliği, çevresel zararlar ve yüksek maliyet daha fazla altyapı oluşturmaya engel bir durum oluşturmaktadır. Bu yüzden araç yoğunluğuna göre süre olarak ayarlanabilenakıllı sinyalizasyon sistemleri hem zaman hem enerji sarfiyatı açısından önerilmektedir. Karayolu trafiğinin kontrol edilmesinde öncelikli amaç, yaya ve taşıt emniyetinin tesis edilmesi ve trafik kazalarının önlenmesidir. Bunun yanı sıra, gecikmelerin azaltılması, ortalama ulaşım hızının arttırılması ve yakıt tüketiminin azaltılması gibi faydaları da amaçlanabilir. Bütün bu amaçlara ulaşmak, trafiğin kontrolü ile elde edilmek istenen faydaları maksimum seviyeye çıkarılması anlamına gelmektedir. Kaydedilen verilere dayanılarak geliştirilen geleneksel denetleyiciler, zamana göre değişen trafik hacimlerine ve yolda artan araç sayısına bağlı olarak trafik kavşaklarına artık çözüm olamamaktadır. İnsan düşüncesine eşit şekilde ulaşmayı sağlayacak trafik denetleyicileri, bulanık mantık gibi teknikleri kullanılarak tasarlanmaktadır.

$\mathrm{Bu}$ makalenin hazırlanmasıyla ilgili literatürde bulunan bazı akademik çalışmalar özetlenmiştir. Tek kavşak kontrolünü gerçekleştirmek için bir sürü çalışmalar gerçekleştirilmiştir. dört yönlü bir trafik kavşağı sinyalizasyon sistemi, bulanık mantık yöntemi ile yapılmıştır. Bu çalışmada, trafik yoğunluğu elektronik devreler ile sanal olarak oluşturulmuş ve deney sistemi bu düzenek ile denenmiştir. Çalışma sonucunda, sadece sabah trafiğinde normal trafik sinyalizasyonu, bulanık mantık denetimi ile yapılan trafik sinyalizasyonuna göre gecikme ve bekleme parametrelerinde \% 19'luk bir üstünlük sağlamıştır. Fakat diğer tüm durumlarda bulanık denetimli trafik sinyalizasyon sistemi, normal sisteme göre gecikme ve bekleme parametrelerinde en az \% 45 ' lik üstünlük sağlamıştır (Demirci, 2007).

Syed (2009), sabit zamanlı modellere dayanan geleneksel trafik sinyal kontrolü yöntemlerinin, değişken ve karmaşık trafik durumuyla etkin bir şekilde başa çıkamadığı syed tarafından öngörülmüştür. Herhangi bir trafik akışı, analiz oluşturmadan, sinyali değiştirmek için önceden ayarlanmış döngü süresine göre model alır. Sabit çevrim süresinden dolayı, bu sistemler hangi kesişimin daha fazla trafik yüküne sahip olduğunu dikkate almaz. Bu sebeple daha uzun süre yeşil 1şık yanmalı ya da tam döngü süresinden daha önce sona ermelidir. Bulanık kural tabanlı denetleyicilerin, bu gibi senaryolarda trafik 1şığı sisteminin iyi yöneticileri olduğu kanıtlanmıştır. Bulanık denetleyicilerin optimum karar alma yetenekleri mevcuttur. Bu algoritmalar, araçların bekleme sürelerini azaltarak, insan güvenliği ve ekonomik verimliliği sürekli olarak geliştirmektedir. Sonuç olarak bulanık denetleyiciler, sinyalleri daha etkili hale getirir ve trafik akışını kolaylaştırır (Syed M. S. , Syed A. \&Humera N. , 2009).

Wang ile arkadaşlarının yaptıkları çalışmanın mantığı, "daha fazla", "daha az", "daha uzun" vb. gibi terimlerle ilgili resmi bir yöntem sunulması üzerinedir ve bu yöntemi "kuzeyden güneye daha fazla trafik varsa, 1şıklar daha uzun süre yeşil kalmalıdır" şeklinde ifade etmiştir. Bulanık mantık denetleyicisi, bir sonraki duruma geçmeden önce trafik 1şığının belirli bir durumda kalmasını gerektiren süreyi belirler. Durumların sırası önceden belirlenir, ancak belirli bir yönde trafik yoksa denetleyici bu durumu atlayabilir. İlerleyen ve bekleyen araçların miktarı; birçok, orta ve hiçbiri gibi bulanık değişkenlere bölünür. Değişkenlerin belirli bir durumdaki aktivasyonu bir üyelik işlevi tarafından verilir, bu nedenle sırada 5 araba olduğunda, bu, "çoğu" ve "\% 75" ortalamanın \% 25 'inin aktivasyonu ile sonuçlanabilir. Mevcut durumun süresinin uzatılıp uzatılmayacağını belirlemek için bulanık kurallar kullanılır. Deneylerde bulanık mantık denetleyicilerinin, trafiğin daha düzenli akmasına izin verip, bekleme süresini azalttığı görülmüştür. Bir dezavantaj; kontrolörün, bulanık değişkenler için önceden ayarlanmış miktar değerlerine bağımlılığıdır. Bu duruma göre toplam trafik miktarı değişir ve doygun bir noktaya ulaşırsa, sistemin bozulmasına neden olabilir (Wang, J, Gao, J. \&Wang, M. , 2004).

Gerçek zamanlı trafik kontrolü için iki aşamalı bir trafik ışı̆̆ı sistemi Allam tarafında önerilmiştir. İzole edilmiş sinyalize bir trafik ışı̆̆ının fazını ve yeşil zamanını dinamik olarak yönlendirmeyi amaçlayan Alam, farklı trafik akış oranlarında ortalama araç gecikmesini azaltmak amaciyla; kavşakta iki trafik acil durum karar modülü (TUDM) ve uzatma süresi karar modülü (ETDM) nü kullanmıştır. İlk aşamada TUDM, tüm kırmızı evreler için aciliyeti hesaplamaktadır. Acil durum derecesine dayanarak, geçiş yapmanın bir sonraki adımında karşılaşılan önemli trafik aciliyeti için kırmızı 1şık devri oluşturur. İkinci aşamada, ETDM, yeşil ışığı hesaplar; araç sayısına bağlı olarak çalışan acil faz, uzatma süresine bağlıdır. Bahsedilen yazılım, bulanık mantığa dayalı izole edilmiş bir sinyal birleşim biriminin durumunu simüle etmek için Matlab'ta geliştirilmiştir. Bulanık mantık kullanan iki kademeli trafik 1şık sistemi, sistemin esnekliği sayesinde sabit zaman sistemi kullanan modellerden, hatta araçla çalıştırılan sistemlerden daha iyi performans göstermiştir (Allam, 2015). 
Bulanık mantık tabanlı trafik yönetim sisteminin test edilmesi ve değerlendirilmesi için tasarlanmış bir simülasyon ortamı fikri taha ve arkadaşları tarafından ortaya atmışlardır. Kullanıcı, birden fazla şeritli trafikte, izole edilmiş kavşak veya kavşak ağını simüle edebilir. Ayrıca girdi parametrelerini belirtebilir, trafik akışını kontrol eden bulanık kurallar oluşturabilir ve çıktı parametrelerini inceleyerek modelin verimliliğini takip edebilir. Bir grafik kullanıcı ara birimiyle, simülasyonun araç hareketlerinin animasyonu da dâhil olmak üzere görselleştirilmesini sağlamıştır (Tahaa M. \&Ibrahim L. 2012).

Trafik modeli ve trafik denetleyicisi modeli 2014 yılında jabalpur tarafından yapılan çalışmada Matlab yazılımını kullanarak geliştirmiştir. Tek çıkışlı ve çok girişli kuyruk teorisi modelini çalışmasında temel almaktadır. Matlab'ta "SimEvent” araç kutusu kullanılmıştır. Trafik denetleyicisi, Matlab'ta bulanık çıkarım sistemin yöntemi kullanılarak geliştirilmiştir. Acil araç hareketini algılayan sensörler ambulans, itfaiye, polis vb. araçlara öncelik verir ve durumun aciliyetine ve şekline göre tercih edilen sinyali iletmektedir (Jha, M. \&Shukla, S. 2014).

$\mathrm{Bu}$ makalede dört yollu bir kavşaktaki trafik 1şıkları için hem akıllı hem de klasik (sabit zaman) denetleyiciler ile kontrol uygulaması yapılmıştır. Akıllı denetleyici olarak bulanık mantıK kullanılmıştır. Bulanık Mantık denitleyicisinde kavşaktaki her yolun trafik yoğunluğna göre hangi yolun yeşil lambasının 1şı̆̆ı yanacak ve o yeşil 1şığın süreleri ayarlanabilmiştir. Klasik (sabit zamanlı)yöntemde ise belirli bir sırada ve sabit bir zamanlı olarak trafik ışıklarının yanıp sönmesi kontrol edilmektedir. Sonuç olarak, tek kavşak için iki yöntemde elde edilen veriler karşıllaştırılmıştır.

\section{Materyal ve Metod}

\subsection{Bulanık Mantık Denetleyicisi}

"Bulanık" kelime anlamı olarak net olmayan veya belirsiz olan şeyleri ifade eder. Sürekli değişen herhangi bir olay, süreç ya da işlev her zaman doğru ya da yanlış olarak tanımlanamaz. Bu tür durumlar "bulanık" olarak betimlenir [8].Bulanık mantığı; modern bilgisayarın dayandığı, her zamanki "doğru veya yanlış" (1 veya 0) Boole mantığı yerine "doğruluk derecelerine" dayalı bir hesaplama yaklaşımıdır[n]. Bulanık mantık fikri ilk olarak 1960'larda Berkeley'deki California Üniversitesi'nden Dr. Lotfi Zadeh tarafından geliştirilmiştir. Zadeh, bilgisayar ortamında doğal dil anlayışı üzerine çalışmaktaydı. Çalışmaları sonucu bulanık mantık denetleyicileri üzerine yoğunlaştı ve yaklaşımını geliştirdi. Bulanık mantık, mühendisler (elektrik, mekanik, sivil, kimyasal, havacılık, tarımsal, biyomedikal, bilgisayar, çevresel, jeolojik, endüstriyel ve mekatronik), matematikçiler, bilgisayar yazılım geliştiricileri dâhil olmak üzere araştırma ve geliştirme üzerine çalışan birçok kişi için son derece yararlı görülmektedir (Bayen, A. , Grieder, P. \& Tomlin, C. 2002).

Bulanık mantığın işletilmesi için sayı veya açıklamalarla temsil edilmesi gerekir. Örneğin, hız 5 m/s değerine "yavaş" açıklaması verilebilir. "Yavaş" terimi, farklı kişiler tarafından kullanıldığında farklı anlamlara sahip olabilir ve gözlemlenen çevreye göre yorumlanmalıdır. Bazı değerlerin sınıflandırılması kolaydır, diğerleri ise farklı durumlara dair insan anlayışı nedeniyle belirlemesi zor olabilir. Biri "yavaş" diyebilir, diğeri ise aynı hızı tanımlarken "hızlı değil" diyebilir. Bu farklılıklar, bulanık kümeler yardımıyla ayırt edilebilir (Bayen, A. , Grieder, P. \& Tomlin, C. 2002).

Bu makalede, 4 yollu bir kavşaktaki trafik 1şıklarının bulanık mantık tabanlı akıllı bir denetim mekanizması ile kontrol çalışması sunulmuştur. Sistemin modellenmesinde kural tabanlı Mamdani tipi bulanık modelleme tekniği kullanılmıştır. Araç yoğunluğu, cadde seçimi ve yeşil süresi sistem parametreleri olarak belirlenmiş ve bu parametreler bulanık mantık tarafından tanımlanmıştır. Giriş parametreleri 4 yolun ayrı ayrı araç yoğunlukları, çıkış parametreleri ise 4 yolun ayrı ayrı yeşil 1şık süreleri ve cadde seçimi olarak tanımlanmıştır. Gündelik hayattaki bir kavşakta yapılan gözlemin ardından her bir kavşak için araç yoğunluğu 0-60 araç, yeşil ışık süresi ise 0-10 saniye arasında olacak şekilde trafik yoğunluğuna göre bu süre azaltılıp veya artırılacağına karar verilir. Giriş parametreleri bulanıklaştırılarak, her caddede araba yoğunluğunu “az", "orta”, “yüksek” gibi değerlerini içerdiği gösterilir. Çıkış parametreleri ise bulanıklaştırılarak ikiye ayrılmaktadır. Birincisi, çıkış yoğunluğuna göre hangi caddenin seçileceğine karar verirken, diğeri çıkış cadde seçildikten sonra tekrar yoğunluğa göre seçilen caddede yeşil süresi "sabit", "azalt", "yukselt" olarak belirlenmiştir. Farklı araç yoğunlukları için kırmızı 1şık sürelerindeki değişim gözlemlenmiştir. Elde edilen sonuçlara göre, bulanık mantık metoduyla kontrol edilen sistemlerin gündelik hayattaki sabit döngü süresi ile çalışan sistemlere göre daha etkili ve verimli şekilde çalıştı̆̆ 1 gözlenmiştir. Sistemin bulanık mantık tabanlı modellemesi bilgisayar ortamında yapılmıştır. Bu ortamda, sisteme ait giriş ve çıkış parametrelerinin belirlenmesi, her bir parametreye ait bulanık küme oluşturulması ve bu sistemin çalışması için kuralların belirlenmesi aşamaları mevcuttur. Oluşturulan kurallar ile sistemin eğitilmesi sonucunda, istenen giriş değerlerine göre çıkış değerleri elde edilmiştir (Zade, A.R. \& Dandekar, D.R. 2012). Bu çalışmada kullanılan Mamdani tip bulanık mantık modeli "Bulanıklaştırma", "Kural Tabanı" ve "Berraklaştırma” olmak üzere üç ana kısımdan oluşmaktadır. Dört giriş ve bir çıkıştan oluşan sistemin elde edilen modeli Şekil 1' ve Şekil 2'de görülmektedir.

\subsection{Bulanık Mantığı ile Tekli Kavşak Kontrolü}

Bulanık kontrol, çok çeşitli otomatik kontrol görevlerine tanıtılmış ve başarıyla uygulanmıştır. Tekli trafik kavşakkontrolünün, bulanık mantık ile nasıl tasarlanıp uygulanacağı açıklanmaktadır. Dinamik kontrol sistemini esas alan bir sistem tasarlanır. Bulanık mantığın kullanıldığı bu sistemin, diğer sistemlerle karşılaştırılması sonuçlar kısmında verilmiştir. Bulanık mantık işleminin ilk aşaması, önerilen bulanık sistemindeki çıktıların hesaplanabilmesi için giriş parametrelerinin sağlanmasıdır. Bu çalışmada, Bir kavşak 
için gün içerisinde toplanmış gerçek veriler kullanılmıştır. Giriş parametresi araba yoğunluğu (her yol için low, medium, high) olarak belirleyerek hangi caddenin yeşil yanması gerektiğini çıkış olarak belirlenmiştir. Caddeyi seçildikten sonra diğer caddelerdeki araba sayısına göre yeşil zamanı ayarlanmaktadır.

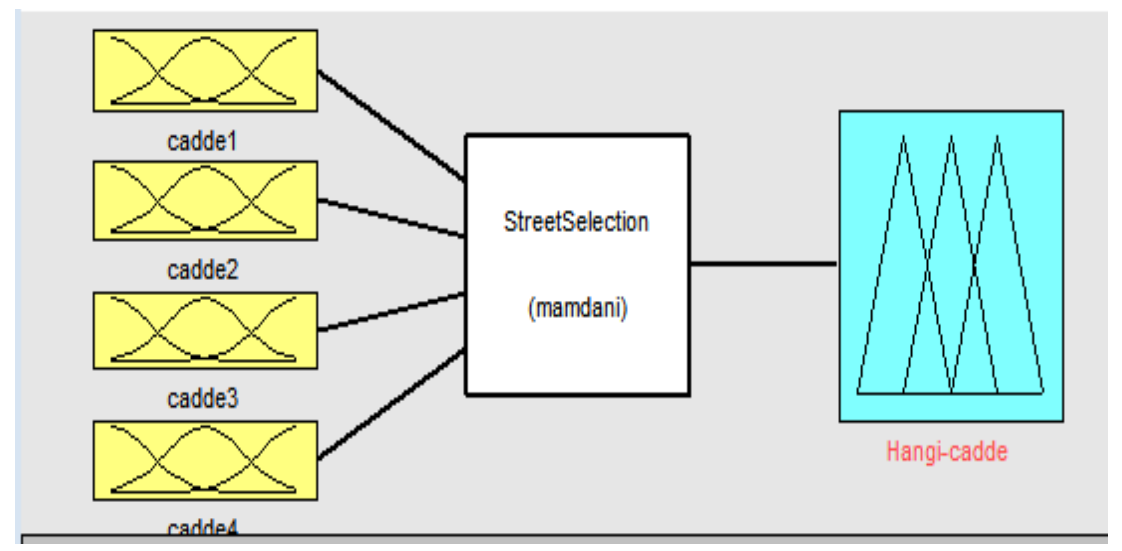

Şekil 1. Sistemin cadde seçimi için Mamdani tip bulanık mantık modeli

\subsubsection{Bulanıklaştırma}

Bulanık mantık modelleme sırasında giriş-çıkış parametrelerini belirledikten sonra her birisinin farklı fonksiyon kümeleri oluşturulur. Bu fonksiyon kümeleri oluşturulurken, giriş-çıkış değerlerinin kaç tane dilsel değişkenle isimlendirileceğine karar verilir. $\mathrm{Bu}$ aşamadan sonra üyelik fonksiyonu çeşitlerinden hangisinin kullanılacağı belirlenir. Bu çalışmada, giriş ve çıkış parametresi olarak seçilen araç yoğunluğu, cadde seçimi ve yeşil ışık süresi; modelleme sırasında Gauss üyelik fonksiyonu kullanılmıştır. Kavşaktaki yollar sırasılyla cadde1, cadde2, cadde3 ve cadde4 olarak isimlendirilmiş ve giriş parametresi için her yolun araç yoğunluğu "az", "orta", "yüksek" şeklinde adlandırılarak sisteme tanıtılmıştır. Belirtilen dört yol için ayrı ayrı araç yoğunlukları 0-60 araç aralığ şeklinde belirlenmiş ve üç farklı gauss üyelik fonksiyonu tanımlanmıştır. Bunlar, cadde seçiminde giriş üyelik fonksiyonlarında her caddede trafik yoğunluğu; "az", "orta” ve "yüksek” tir. Yeşil ışık süresi kontrolü için giriş üyelik fonksiyonlarında; "az-trafik”, "ortatrafik" ve "yüksek trafik” şeklinde tanımlanır. Cadde seçiminde ise çıkış fonksiyonlarında; "cadde-1", "cadde-2”, “cadde-3”, "cadde4" tür. Yeşil ışık süresi için çıkış fonksiyonlarında; "sabit”, "azalt”, “yükselt" tir. Yollara ait giriş ve çıkış üyelik fonksiyonları Şekil 2'de görülmektedir.



Şekil 2. Cadde Seçiminde Giriş Üyelik Fonksiyonları 


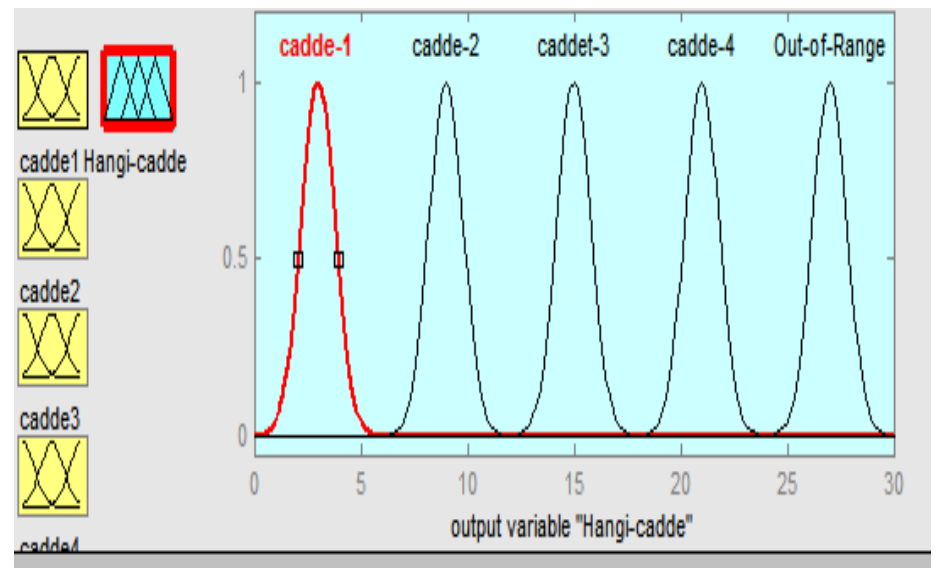

Şekil 3. Cadde Seçimi İçin Çıkış Üyelik Fonksiyonları

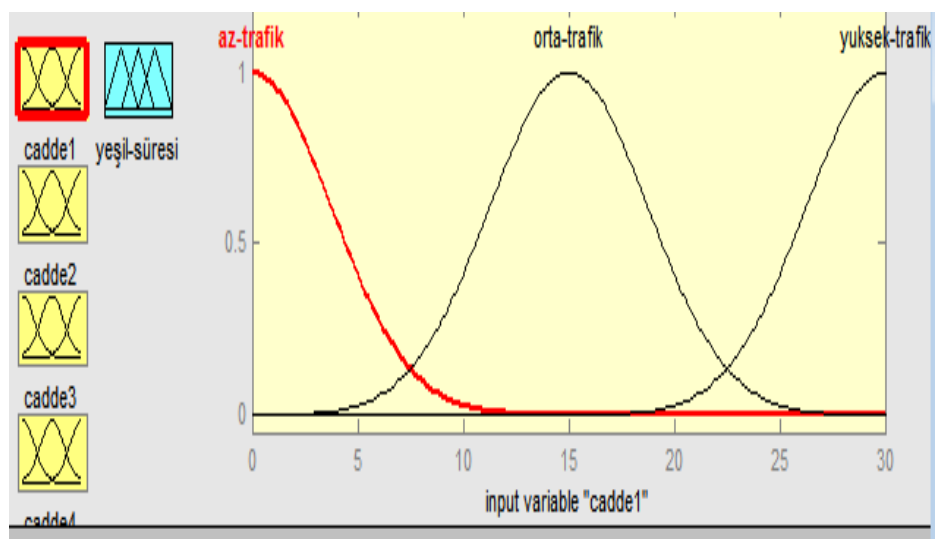

Şekil 4. Yeşil Işık Süresi İçin Giriş Üyelik Fonksiyonları

\subsubsection{Kural Tabant}

$\mathrm{Bu}$ çalışmada sistemin akıllı kontrol mekanizması altında çalışmasının sağlanması için toplamda 101 kural oluşturulmuştur. Bu kurallar oluşturulurken iki adım izlenmiştir: Birinci adımda, kavşaktaki her yolun içerisinde trafik yoğunluğu yüksek olan cadde seçilecektir. İkinci adımda ise, cadde seçildikten sonra tekrar diğer caddelerin trafik yoğunluğuna bakılır ve ona göre yeşil süresi azaltıp artırılır ya da sabit tutulur. Şekil 5’te ve Şekil 6'da yazılmış kuralların bir kısmı gösterilmiştir.

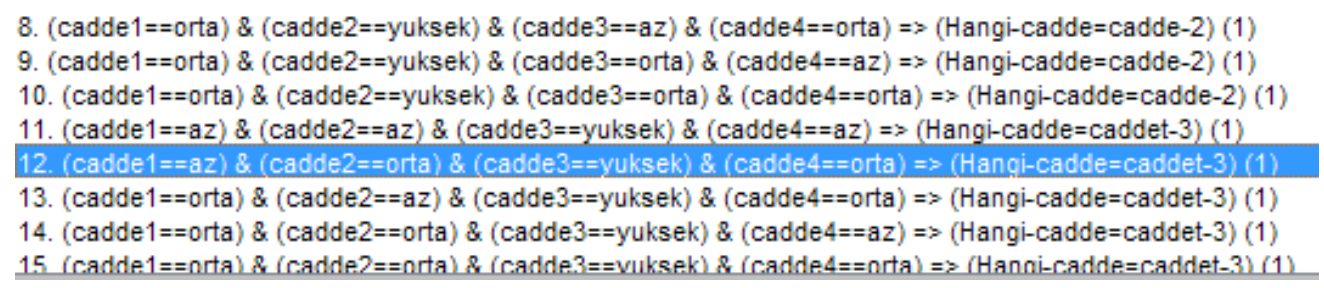

Şekil 5. Cadde Seçimi İçin Kural Tabanı

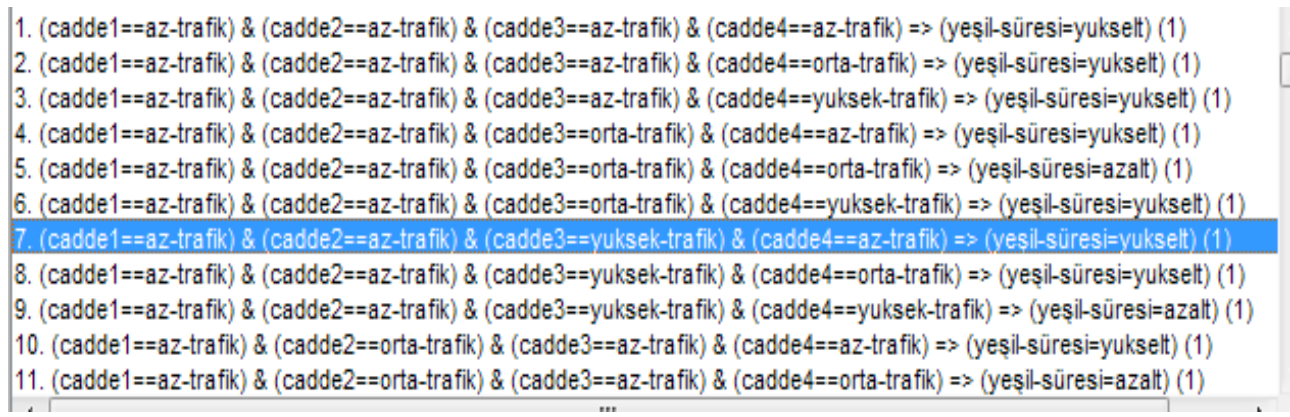

Şekil 6. Yeşil 1şık süresi için kural tabanı

.Örneğin; Şekil 5'teki 12. kural, kavşakta cadde2 ve cadde4 yollarının “orta ”, Cadde1 yolunun "az", cadde3 yolunun ise "yüksek" yoğunlukta olduğu durumda, cadde-3 yolunun yeşil lambası yanacaktır. Cadde seçildikten sonra yeşil süresi azaltılıp 
artırılacağına karar verilecektir. Şekil 6'daki 7. kural, kavşakta cadde1, cadde2 ve cadde4 yollarının "az", Cadde3 yolunun "yüksek" yoğunlukta olduğu durumda, cadde-3 yolunun yeşil süresi artırılacaktır.

\subsubsection{Durulaștırma}

Bulanık mantık modellemenin takiben elde edilen bulanık sonuç kümesinin tam bir değere dönüştürülmesi işlemine, durulaştırma denir. Ağırlık merkezi, toplamların merkezi, maksimum ortalaması vb. gibi birkaç durulaştırma metodu mevcuttur. Bu çalışmada durulaştırma işlemi için ağırlık merkezi yöntemi kullanılmıştır. Ağırlık merkezi yöntemi en yaygın olarak kullanılan yöntemlerden biridir. Yöntem ile oluşan çıkarım kümesinde ağırlık merkezi bulunur ve keskin değer olarak bu merkeze karşılık gelen değere alınır. Oluşan her tür çıkarım kümesine çözüm bulması, çok yaygın olarak kullanılmasının en önemli nedenidir ( Pfluger, N., Yen, J., \& Langari, R. 1992).

$\mathrm{Bu}$ çalışmanın amacı, gözlem yoluyla elde edilen verilerin yardımıyla bir kavşaktaki yol seçimi ve yeşil süresinin akıllı kontrol mekanizması altındaki çalışma performanslarının, BM modelleme tekniği ile modellenmesidir. Performans parametreleri, araç yoğunluğu, yol seçimi ve trafik 1şıklarının yeşil 1şı süresi olarak belirlenmiştir. Sistemin girişi ile çıkışı arasındaki ilişkiyi tanımlayan ve bulanık mantık denetleyicinin davranışlarını tespit eden denetim kuralları oluşturulmuştur. Bu kuralların sonucu olarak, sistem girişine uygulanan farklı araç yoğunluğuna ait yolun seçilmesi ve yeşil 1şıkların yanma sürelerindeki istenen değişim görülmüştür.

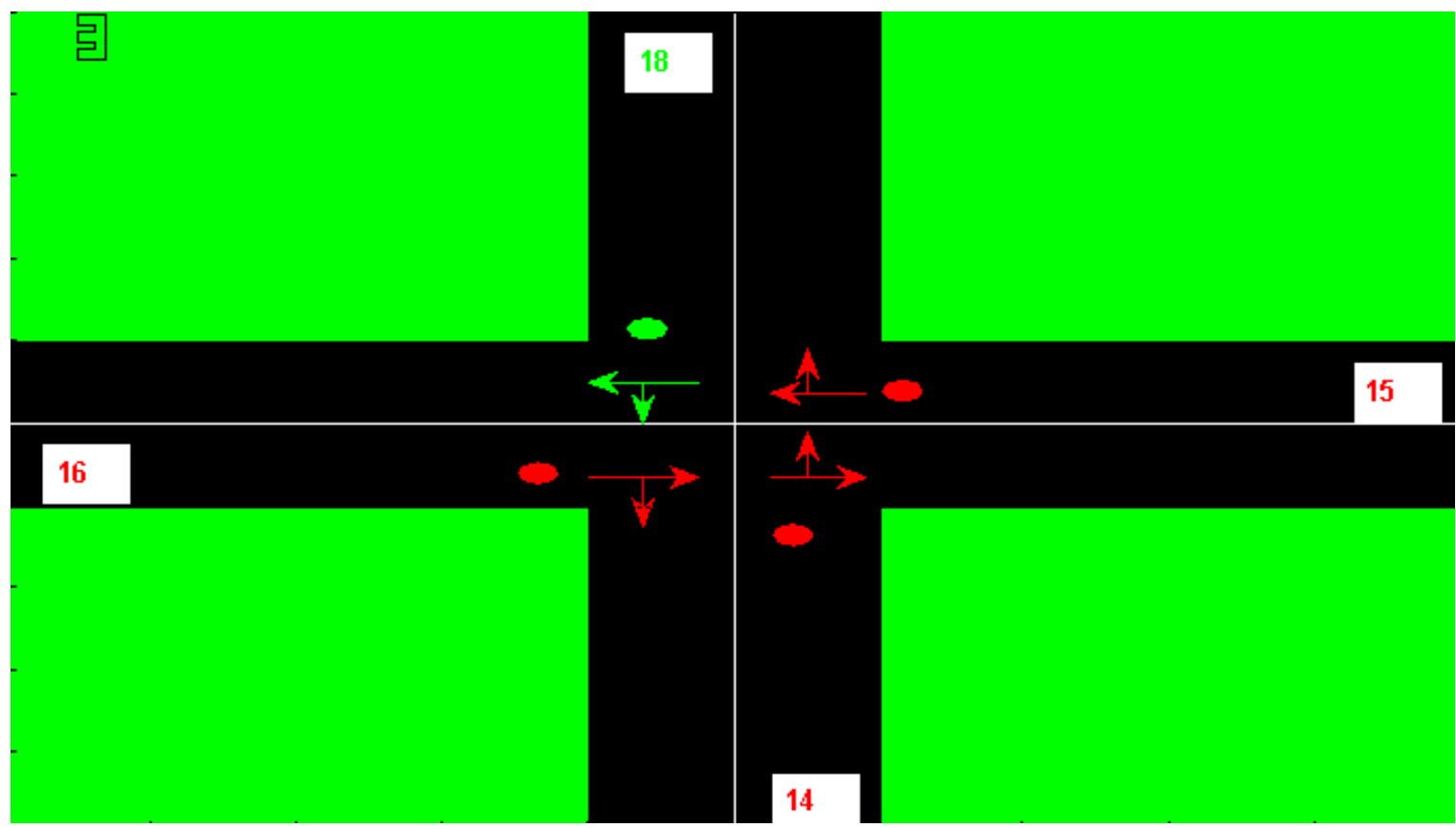

Şekil 7. Tekli kavşak similasyonu

\section{Araştırma Sonuçları ve Tartışma}

\subsection{Sistem Çalıșması}

Bu çalışmanın amacı 4 yollu bir kavşağa ait elimizdeki gerçek verileri, bulanık mantığı ve (klasik) sabit zaman yöntemi ile değerlendirerek hangi yöntemin daha verimli olduğunu göstermektir. Bulanık mantığı yönteminde araç yoğunluğu ve trafik 1şıklarının yeşil ışı süresi "performans parametreleri” olarak belirlenmiştir. Bu parametrelere dayanarak giriş ile çıkış arasında ilişkilendiren bulanık sistem tabanında, kural kümeleri olmuştur. Sonuç olarak, sistem girişine uygulanan ve farklı araç yoğunluğuna bağlı yeşil ışıkların yanma sürelerindeki ve yanma sıralamalarındaki istenen değişim görülmüş̧ür. Çalışmanın sonunda bulanık mantık yöntemiyle elde edilen veriler Tablo 1'de, ve klasik yöntemiyle elde edilen veriler tablo 2'de gösterilmiştir. 
Tablo 1. Kavşaktaki Caddelere Ait 20 Devir İçin Bulanık Mantık Yöntemiyle Elde Edilen Veriler

\begin{tabular}{|c|c|c|c|c|c|c|}
\hline $\begin{array}{c}\text { Devir } \\
\text { numaras1 }\end{array}$ & 1.Cadde & 2.Cadde & 3.Cadde & 4.Cadde & $\begin{array}{c}\text { Kavşaktan geçen } \\
\text { araba say1s1 }\end{array}$ & $\begin{array}{c}\text { Toplam } \\
\text { zaman(s) }\end{array}$ \\
\hline 1 & 12.0 & 0.0 & 7.0 & 5.0 & 24.0 & 14.0 \\
\hline 2 & 2.0 & 8.0 & 7.0 & 4.0 & 21.0 & 15.0 \\
\hline 3 & 1.0 & 14.0 & 14.0 & 14.0 & 40.0 & 38.0 \\
\hline 4 & 13.0 & 5.0 & 6.0 & 10.0 & 32.0 & 35.0 \\
\hline 5 & 11.0 & 12.0 & 1.0 & 6.0 & 27.0 & 35.0 \\
\hline 6 & 0.0 & 11.0 & 4.0 & 1.0 & 16.0 & 22.0 \\
\hline 7 & 13.0 & 11.0 & 10.0 & 11.0 & 29.0 & 50.0 \\
\hline 8 & 13.0 & 15.0 & 14.0 & 13.0 & 22.0 & 52.0 \\
\hline 9 & 16.0 & 9.0 & 23.0 & 8.0 & 21.0 & 51.0 \\
\hline 10 & 20.0 & 13.0 & 10.0 & 9.0 & 21.0 & 53.0 \\
\hline 11 & 15.0 & 17.0 & 21.0 & 23.0 & 19.0 & 52.0 \\
\hline 12 & 27.0 & 19.0 & 25.0 & 20.0 & 16.0 & 49.0 \\
\hline 13 & 24.0 & 33.0 & 23.0 & 20.0 & 17.0 & 53.0 \\
\hline 14 & 20.0 & 32.0 & 30.0 & 20.0 & 17.0 & 53.0 \\
\hline 15 & 31.0 & 32.0 & 28.0 & 22.0 & 16.0 & 54.0 \\
\hline 16 & 31.0 & 28.0 & 33.0 & 35.0 & 15.0 & 54.0 \\
\hline 17 & 39.0 & 31.0 & 40.0 & 34.0 & 14.0 & 52.0 \\
\hline 18 & 37.0 & 44.0 & 37.0 & 42.0 & 14.0 & 54.0 \\
\hline 19 & 49.0 & 43.0 & 38.0 & 42.0 & 13.0 & 52.0 \\
\hline 20 & 41.0 & 52.0 & 50.0 & 43.0 & 13.0 & 54.0 \\
\hline & & & & & & \\
\hline
\end{tabular}

Tablo 2. Kavşaktaki caddelere ait 20 devir için klasik yöntemiyle elde edilen veriler

\begin{tabular}{|c|c|c|c|c|c|c|}
\hline $\begin{array}{c}\text { Devir } \\
\text { numaras1 }\end{array}$ & 1. Cadde & 2.Cadde & 3.Cadde & 4.Cadde & $\begin{array}{c}\text { Kavşaktan } \\
\text { geçen araba } \\
\text { say1s1 }\end{array}$ & $\begin{array}{c}\text { Toplam } \\
\text { zaman(s) }\end{array}$ \\
\hline 1 & 12.0 & 0.0 & 7.0 & 5.0 & 24.0 & 44.6 \\
\hline 2 & 2.0 & 8.0 & 7.0 & 4.0 & 21.0 & 44.6 \\
\hline 3 & 1.0 & 14.0 & 14.0 & 14.0 & 28.0 & 44.6 \\
\hline 4 & 12.0 & 9.0 & 10.0 & 15.0 & 30.0 & 44.6 \\
\hline 5 & 13.0 & 14.0 & 3.0 & 14.0 & 23.0 & 44.6 \\
\hline 6 & 6.0 & 16.0 & 3.0 & 9.0 & 21.0 & 44.6 \\
\hline 7 & 13.0 & 21.0 & 10.0 & 14.0 & 22.0 & 44.6 \\
\hline 8 & 13.0 & 27.0 & 17.0 & 18.0 & 22.0 & 44.6 \\
\hline 9 & 14.0 & 22.0 & 26.0 & 14.0 & 20.0 & 44.6 \\
\hline 10 & 18.0 & 21.0 & 24.0 & 10.0 & 20.0 & 44.6 \\
\hline 11 & 24.0 & 25.0 & 30.0 & 19.0 & 17.0 & 44.6 \\
\hline 12 & 31.0 & 28.0 & 34.0 & 22.0 & 16.0 & 44.6 \\
\hline 13 & 32.0 & 38.0 & 36.0 & 18.0 & 17.0 & 44.6 \\
\hline 14 & 28.0 & 45.0 & 39.0 & 14.0 & 16.0 & 44.6 \\
\hline 15 & 35.0 & 49.0 & 42.0 & 12.0 & 16.0 & 44.6 \\
\hline 16 & 35.0 & 49.0 & 47.0 & 21.0 & 14.0 & 44.6 \\
\hline 17 & 43.0 & 49.0 & 54.0 & 24.0 & 12.0 & 44.6 \\
\hline 18 & 45.0 & 59.0 & 55.0 & 29.0 & 13.0 & 44.6 \\
\hline 19 & 54.0 & 62.0 & 52.0 & 33.0 & 13.0 & 44.6 \\
\hline 20 & 53.0 & 71.0 & 60.0 & 31.0 & 12.0 & 44.6 \\
\hline & & & & & & \\
\hline
\end{tabular}




\section{Sonuç}

$\mathrm{Bu}$ makale çalışmasında bulanık mantık ve klasik yöntemleriyle trafik sinyalizasyon kontrolü gerçekleştirilmiştir. Bulanık mantık temel yapısı ve trafik kontrolünde kullanılması gösterilmiştir. Nihayetinde klasik yöntemi ile yapılan trafik kontrolü ve bulanık mantığı ile yapılan trafik kontrolü ile karşılaştırma gerçekleştirilmiştir.

Tablo 3. Klasik yöntemi ile yapılan trafik kontrolü ve bulanık mantı̆̆ 1 ile yapılan trafik kontrolü karşılaştırlması

\begin{tabular}{|c|c|c|}
\hline Yöntem & Geçen araba sayısı & Yeşil süresi \\
\hline Klasik yöntem & 377 & 892 \\
\hline Bulanık mantık & 407 & 892 \\
\hline
\end{tabular}

Tablolarda görüldüğü üzere, bulanık mantık yöntemi kullanılarak 20 devirde kavşaktan toplam geçen araba sayısı 407 ve bu arabaların geçmesi için toplam süre 892 saniyedir. klasik yöntemde ise 892 saniyede kavşaktan çıkan toplam araba sayısı 377 'tir. Elde edilen verilere göre hem ekonomi açısından hem de zaman açısından Bulanık mantık yöntemi ilk sırada görülmektedir, ve son olarak klasik yöntem gözlemlenmiştir.

\section{References}

Demirci, O. (2007). Akıllı Trafik Sinyalizasyonu, Y. Lisans, Kocaeli Üniversitesi, Fen Bilimleri Fakültesi, Sf. 63,64.

Syed M. S. , Syed A. ve Humera N. , (2009). "Fuzzy Rule Based Traffic Signal Control System For Oversaturated Intersections," Cinc, Vol. 2, Pp.162-165, 2009 International Conference On Computational Intelligence And Natural Computing.

Wang, J, Gao, J. ve Wang, M. (2004). Modeling Of Urban Intelligent Traffic Signal Control System Based On CPN [J]. Computer Engineering.

Alam, J. , (2015). “Traffic Light System Using Fuzzy Logic”, Computer Science And Applications, AIMCA, Haldwani, Uttrakhand, India.

Tahaa M. ve Ibrahim L. (2012). “Traffic Simulation System Based On Fuzzy Logic”, Conference Organized By Missouri University Of Science And Technology.

Jha, M. ve Shukla, S. (2014). Design Of Fuzzy Logic Traffic Controller For Isolated Intersections With Emergency Vehicle Priority System Using MATLAB Simulation. Arxiv Preprint Arxiv:1405.0936.

IŞIKLI, Ş. (2008). Bulanık Mantık Ve Bulanık Teknolojiler. Ankara Üniversitesi, DTCF, Felsefe Bölümü, Doktora Öğrencisi Tezi, 119.

Bayen, A. , Grieder, P. ve Tomlin, C. (2002). A Control Theoretic Predictive Model For Sector-Based Air Traffic Flow. In AIAA Guidance, Navigation, And Control Conference And Exhibit (P. 5011).

Zade, A.R. ve Dandekar, D.R. 2012, "Simulation Of Adaptive Traffic Signal Controller İn MATLAB Simulink Based On Fuzzy Inference System", National Conference On Innovative Paradigms İn Engineering \& Technology, 9-13.

Pfluger, N., Yen, J., ve Langari, R. (1992). A Defuzzification Strategy For A Fuzzy Logic Controller Employing Prohibitive İnformation İn Command Formulation. In 92 IEEE Int Conf Fuzzy Syst FUZZ-IEEE (Pp. 717-723). Publ By IEEE. 